\title{
Calorimetry of plant metabolism: A means to rapidly increase agricultural biomass production
}

\author{
Lee D. Hansen ${ }^{\mathrm{a}}$, Bruce N. Smith ${ }^{\mathrm{b}}$, and Richard S. Criddle \\ ${ }^{\circ}$ Department of Chemistry and Biochemistry, Brigham Young University, Provo, UT \\ 84602 \\ ${ }^{b}$ Department of Botany and Range Science, Brigham Young University, Provo, UT \\ 84602 \\ 'Section of Molecular and Cellular Biology, University of California, Davis, CA \\ 95616
}

\begin{abstract}
The green revolution greatly increased total world food and fiber production and productivity per land area, but total biomass production was not increased. Further gains in productivity must come by selection and breeding of faster growing phenotypes optimally matched to the growth environment. Plant respiration rates and growth rates have recently been related by means of a quantitative, physiological model that includes calorimetric measurement of dark metabolic heat rate $(\Phi)$ and $\mathrm{CO}_{2}$ production rate $\left(\mathrm{R}_{\mathrm{CO} 2}\right)$. Laboratory determinations of $\mathrm{R}_{\mathrm{CO} 2}$ and $\Phi$ as functions of environmental variables and application of the model equations produces descriptions of plant growth rates as functions of environmental variables in a few hours to days. These functions may make it feasible to rapidly select for optimum growth within a given environment, and thus to continue the green revolution by rapidly increasing agricultural biomass production.
\end{abstract}

\section{INTRODUCTION}

Present world food production is sufficient for the existing world population, but unless new technology is introduced, the rate of population increase must slow dramatically or future famines will result from inability of agriculture to produce sufficient food $(1,2)$. Fiber production for lumber and paper products is causing rapid depletion of forests in the Amazon basin, equatorial Pacific, northern Russia and Siberia, and in northwestern North America (3). Degradation of resources, population growth, and poverty are linked ir a cycle that diminishes the quality of life (4). Increasing agricultural biomass production could thus contribute to avoidance of future severe societal problems.

During the last three decades, plant breeders have been very successful at increasing agricultural productivity by breeding cultivars with more desirable morphologies, partitioning, disease and predation resistance, and ability to use abundant resources, but total biomass production has not yet been increased by the green revolution. The further large increases in productivity that will be required to meet future needs must conne from greatly increased productivity per plant. One way to gain increased productivity is through identification, selection, breeding, and genetic engineering of plants with increased metabolic capability matched to t $1 e$ environment where they are grown.

Efficient breeding for higher yield requires simultaneous selection for high growth rate in the growih environment and increased partitioning of biomass to the harvestable organ (i.e. improved harvest index). Both factors affect the yield from determinate crops such as cereals harvested at a specific time in their life cycle, but the yield from indeterminate crops such as trees and grass harvested for total biomass is determined almcst solely by the growth rate. This paper only considers methods for improving the growth rate, but an increasid growth rate can benefit production of both kinds of crops. 
Neither plant physiology nor ecology have been particularly useful for guiding plant breeding for increased growth rate or response to environment. Data from these sciences show there is great potential for improving productivity through biotechnology, but to realize this potential, some means for rapidly identifying desirable properties and assessing the possibilities in a new plant variety must be found. Current empirical methods for testing plants require extensive and expensive field trials that take many years to identify and verify the properties of a new plant variety. Field trials are especially difficult with new varieties with unknown climatic responses. Each new variety must be grown in many different climates and for many years before its productivity in different environments can be accurately assessed. In efforts to avoid much of the time and expense of field trials, plant physiologists have long worked to develop models capable of accurately relating rapidly measurable physiological properties to long term growth properties of plants so that rapid and inexpensive selection could be done by means of laboratory measurements.

Most plant physiologists and breeders assume that increasing photosynthesis will automatically lead to increased growth (e.g. see refs. 3, 5-7). This model is implicit or explicit in most current research and textbooks on the ecology and physiology of plant productivity, but no improvement has resulted from decades of effort on photosynthesis (7-9). These workers have failed to realize that an increase in photosynthesis will lead to an increase in growth rate only if the plant can use the increased photosynthate to more rapidly construct structural biomass.

Another model assumes growth rate is limited by availability of a nutrient other than carbon, e.g. N, P, K, and $\mathrm{Fe}$, or water. But again, increasing availability of a nutrient, either by increasing the concentration in the environment or by improving the plant's ability to acquire it, will lead to an increased growth rate only if the added nutrient was limiting the plant growth.

A third model advocates decreasing the loss of respiratory carbon as a means to increase plant productivity. But the role of respiration in plant growth has often been misunderstood because although respiration is a loss of carbon, it is also absolutely necessary for plant growth. Acquistion and processing of raw materials into structural materials (i.e. growth) requires energy from respiration. Thus, an increase in growth rate must be accompanied by an increase in respiration rate and/or substrate carbon conversion efficiency. Many studies have yielded reasonably strong correlations between respiration rate and growth rate. But the correlations are sometimes positive, sometimes negative, and sometimes too weak to be observed. Many workers have attempted to explain these correlations with models that divide respiration into maintenance and growth components. But such a separation of respiratory functions has both conceptual and experimental problems, making the division ambiguous and impossible to accurately quantify.

INPUTS

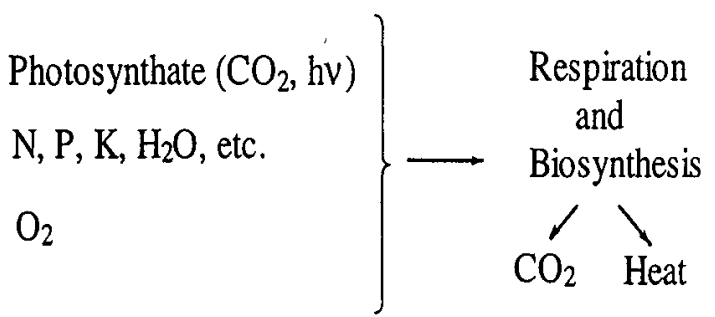

OUTPUT

Structural

Biomass

Rate $\mathrm{x}$ Efficiency $=$ Output rate

$$
\mathrm{R}_{\mathrm{CO} 2}(\varepsilon / 1-\varepsilon)=\mathrm{R}_{\mathrm{SG}}
$$

Fig. 1 Schematic of a unified model for plant growth and metabolism. In this model, growth rate is proportional to the rate of $\mathrm{CO}_{2}$ production times an efficiency function. Growth rate is determined either by the rate of acquisition of a limiting input or by the rate of processing of inputs into biomass. Photosynthesis provides one input to this model, i.e. substrate carbon or photosynthate. 
A unified, physiological model relating metabolism to plant growth can be derived from the fundamenial understanding that plant growth rate may depend on the rate of acquisition of carbon or of other resourcis, or it may depend on the rate and efficiency of processing of those resources into structural biomass, all of which are fuinctions of the environmental conditions and the genetically determined abilities of the plant. This is shown schematically in fig. $1(10)$. This model is analogous to models describing manufacturing processes such as a bicycle factory (11). The rate of production of bicycles may depend on the rate of acquisition of parts or it may depend on the rate and efficiency with which the workers can assemble the parts into bicyclis. Enhancement of the bicycle production rate (or plant biomass production rate) can only be done by improving the rate limiting process, whether it be rate of acquisition of parts (or nutrients including photosynthate) or the rate of assembly of the finished product. To be useful, such a model relating plant metabolism to grow th and environmental responses must be capable of describing both resource-limited and genetically-limited growth in terms of measurable, unambiguous variables. Such variables are defined by the thermodynamics of the growth process.

\section{A THERMODYNAMIC MODEL FOR RELATING PLANT METABOLISM TO GROWTH AND ENVIRONMENT}

Based on the model in fig. 1, specific growth rate $\left(R_{S G}\right)$ can be shown to be equal to the specific rate of respiratory carbon dioxide production $\left(\mathrm{R}_{\mathrm{CO} 2}\right)$ multiplied by a function of the substrate carbon conversion efficiency $(\epsilon)$, eqn. 1

$$
R_{\mathrm{SG}}=\mathrm{R}_{\mathrm{CO} 2}(\epsilon / 1-\epsilon)
$$

where $\epsilon$ is the ratio of moles of carbon retained in new structural biomass to total moles of carbon, i.e. moles of respiratory $\mathrm{CO}_{2}$ plus moles of $\mathrm{C}$ in new structural biomass (12). Equation 1 is valid under all reasonat le conditions, including photosynthate and nutrient limitations.

Respiratory $\mathrm{CO}_{2}$ rates have routinely been measured on plants and plant tissues for many years, but evaluation of $\epsilon$ has been difficult. In the only study to directly measure $\epsilon$ as a function of temperature, Yamaguchi (13) determined substrate carbon conversion efficiency of rice, soybean, and maize seedlings at several temperatures by measuring the mass of carbon converted to structural biomass and the mass of carbon lost as $\mathrm{CO}_{2}$ during growth of the seedling. Although this method appears to give accurate results, it is slow, lacks sensitivity, is labor-intensive, and requires total destruction of the plant.

In work done in the last few years we have developed equations describing plant growth in terms of respiratory $\mathrm{CO}_{2}$ and heat rates of plant tissues (12). These equations show that relative values for the $\epsilon$ function in eqn. 1 can be obtained from $\mathrm{R}_{\mathrm{CO} 2}$ and metabolic heat rates measured simultaneously on the same plant or tisside sample. We have also developed calorimetric methods for essentially simultaneous measurement of metabolic heat and $\mathrm{CO}_{2}$ rates $(14,15)$.

The ratio of metabolic heat rate $\Phi$ to the $\mathrm{CO}_{2}$ rate is a linear function of $(\epsilon / 1-\epsilon)$ as shown in eqn. $2(12)$

$$
(\epsilon / 1-\epsilon) \Delta H_{\mathrm{B}}=-\left(\Phi / \mathrm{R}_{\mathrm{CO} 2}\right)-\left(1-\gamma_{\mathrm{p}} / 4\right) \Delta H_{\mathrm{O} 2}
$$

where $\Delta H_{\mathrm{B}}$ is the total enthalpy change for incorporation of one mole of substrate carbon into one mole of biomass carbon, including enthalpy effects from all elements, $\gamma_{\mathrm{P}}$ is the mean oxidation state of the substrate carbon, and $\Delta H_{\mathrm{O} 2}$ is the constant from Thornton's rule $\left(-455 \pm 15 \mathrm{~kJ} \mathrm{~mol}^{-1}\right)(12)$. If the reasonable assumption is made that the composition of the biomass formed and the substrate carbon source remain constant, then $\Delta H_{\mathrm{B}}$ and $\gamma_{\mathrm{P}}$ are constant, and changes in $\Phi / \mathbf{R}_{\mathrm{CO} 2}$ are caused by changes in the efficiency function $(\epsilon / 1-\mathrm{r})$. Absolute values for $\Delta H_{\mathrm{B}}$ and $\gamma_{\mathrm{P}}$ are difficult to obtain, but, for comparison and selection of plants, relative values of performance are often all that are needed. Furthermore, because $\Phi$ and $\mathrm{R}_{\mathrm{CO} 2}$ are both readily measured as functions of environmental variables, $\epsilon$ can be expressed as a function of environmental variables. 
Combination of eqns. 1 and 2 gives the equation for specific growth rate in terms of $\Phi$ and $\mathrm{R}_{\mathrm{CO} 2}$.

$$
\mathrm{R}_{\mathrm{SG}} \Delta H_{\mathrm{B}}=-\mathrm{R}_{\mathrm{CO} 2}\left(1-\gamma_{\mathrm{p}} / 4\right) \Delta H_{\mathrm{O} 2}-\Phi
$$

In this equation the product $\mathrm{R}_{\mathrm{SG}} \Delta H_{\mathrm{B}}$ is a measure of growth rate in terms of the rate of storage of chemi: al energy in structural biomass with substrate as the reference energy state. The rate of energy storage is expressed as the difference between the rate of energy produced by respiration, $R_{\mathrm{CO}_{2}}\left(1-\gamma_{\mathrm{P}} / 4\right) \Delta H_{\mathrm{O} 2}$, and the rate of energy lost to the surroundings, $\Phi$. Again, because $\Phi$ and $\mathrm{R}_{\mathrm{CO} 2}$ are both readily measured as functions of environmental variables, growth rate can also be expressed as a function of environmental variables. We al so note in passing that eqns. 1-3 apply to animals and microorganisms as well as plants.

Definition of growth rate as the rate of accumulation of potential energy is a novel idea that allows direct comparison of plants producing biomass with different composition, e.g. starch and lipids, and thereby increases our understanding of what is meant by "growth". By this definition, growth rate is measured as tile rate of increase in energy content of the plant. Plant scientists have traditionally used the rate of increase in total dry mass of a plant as a measure of growth rate (6). However, including photosynthate is incorrict except over a long time period, or in large plants where the amount of photosynthate is negligible and to al mass measurements are an accurate indication of growth rate. The other common means of measuring plant growth is by measuring the rate of increase in volume, area, or length, which can occur by cell division or yy cell expansion. The difficulty of defining exactly what is meant by these mass and length measures of growth is exemplified by the changes in a maize plant through a day-night cycle. The plant elongates faster at night than during the day, but in doing so loses dry mass through respiration. During the day the plant gains dry mass through photosynthesis, but elongation is slower. Defining growth rate in terms of an energy rate avoids such ambiguities.

Equations 2 and 3 may be simplified by incorporating Thornton's constant and by assuming that substrate carbon is carbohydrate which has a value of $\gamma_{P}$ equal to zero, i.e.

$$
\begin{aligned}
& (\epsilon / 1-\epsilon) \Delta H_{\mathrm{B}}=-\Phi / \mathrm{R}_{\mathrm{CO} 2}+455 \\
& \mathrm{R}_{\mathrm{SG}} \Delta H_{\mathrm{B}}=455 \mathrm{R}_{\mathrm{CO} 2}-\Phi
\end{aligned}
$$

Because of the simplifying assumptions, eqns. 4 and 5 must be altered accordingly to accurately describe systems which are catabolizing significant amounts of lipid or producing significant amounts of fermentation products. Such situations are evident because $\Phi$ becomes greater than or very much less than $455 \mathrm{R}_{\mathrm{CO} 2}$, thus indicating the more complete eqns. 2 and 3 must be used.

\section{TESTS OF THE MODEL}

To date we have tested the validity of our model in three ways. (a) Does it correctly predict relative values for measured growth rates of plants? (b) Does it correctly predict the responses of plants to changes in the environmental temperature? And, (c) does it adequately explain the nature and variability of the many observed correlations between respiration rates and growth rates?

\section{Comparison of Measured and Predicted Growth Rates}

Figure 2 compares mass growth rates of seedlings of five maize cultivars, each measured at three temperatur is and predicted from eqn. 5 from calorimetric measurements at the same temperatures. The results are in agreement within the uncertainties of the methods. 


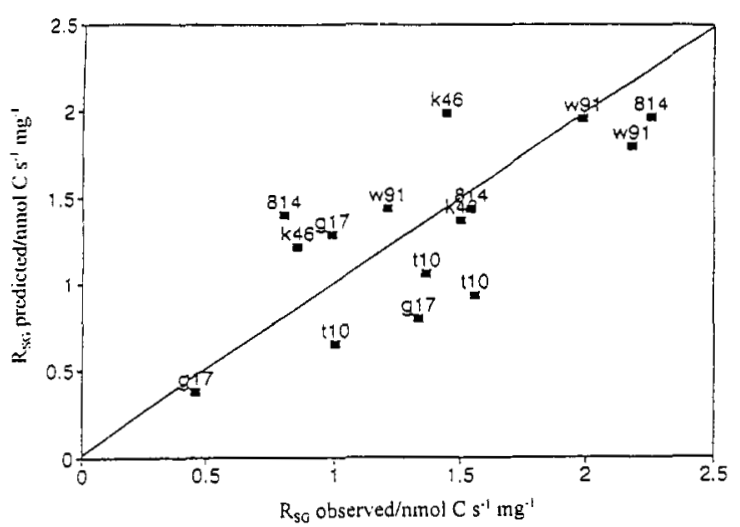

Fig. 2 Measured growth rates of maize cultivars versus growth rates predicted from calorimetric measurements of respiratory heat and $\mathrm{CO}_{2}$ rates. Measurements were made at three temperatures for each cultivar. Data are from D. R. Rank, Ph.D. Dissertation, University of California, Davis, 1996.

\section{Effects of Environmental Temperature}

Figure 3 shows growth rates of several maize cultivars calculated as functions of temperature from $\Phi$ and $\mathrm{R}_{\mathrm{CO} 2}$ values measured at only two temperatures, 15 and $25^{\circ} \mathrm{C}$. The growth curves were calculated from eqn. 5 by assuming $\Phi$ and $\mathrm{R}_{\mathrm{CO} 2}$ are described as functions of temperature by Arrhenius functions, eqns. 6 and 7

$$
\begin{aligned}
& \phi=A_{\phi} \mathrm{e}^{-\mu_{\phi} / T} \\
& \mathrm{R}_{\mathrm{CO} 2}=A_{\mathrm{CO}_{2}} \mathrm{e}^{-\mu \mathrm{CO}_{2} / T}
\end{aligned}
$$

where $\mu$ is the temperature coefficient and $A$ is a constant. The results correctly predict, from measurements made far from any temperature that would damage the tissues, a ranking of the cultivars according to where they are grown from north to south that agrees well with empirically derived planting practices for these cultivars. This study of maize cultivars (16) further showed that $\mu_{\phi}$ was not correlated with $\mu_{\mathrm{CO} 2}$. Similar results obtained for poplar, sagebrush, yarrow, cheatgrass, and several other species indicate that in general $\mu_{\phi}$ is not correlated with or equal to $\mu_{\mathrm{CO} 2}$.

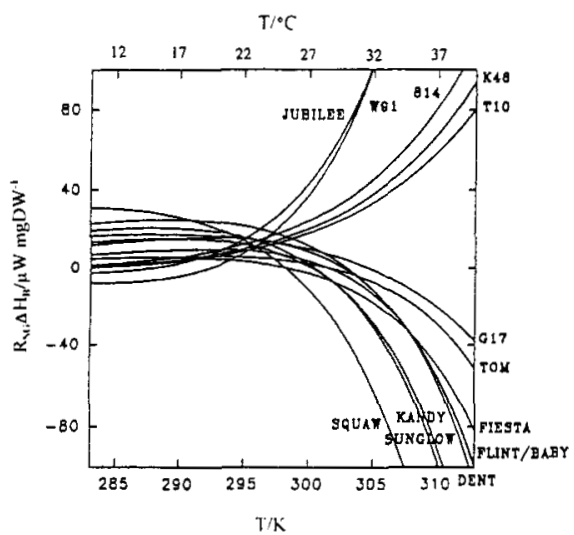

Fig. 3 Growth rates of maize cultivars calculated from respiratory heat and $\mathrm{CO}_{2}$ rates measured at 15 and $25^{\circ} \mathrm{C}$. The extrapolated portions of the curves are valid only to the extent that metabolic heat and $\mathrm{CO}_{2}$ rates are described by Arrhenius functions. Data are from ref. 16. 
Growth-temperature curves calculated from simultaneous measurements of $\Phi$ and $\mathrm{R}_{\mathrm{CO} 2}$ at several temperatures covering the growth range (which thus avoid the assumption of Arrhenius behavior made in producing fig. 3) provide an even better description of and insights into the physiology of plant response to temperature (17). Figure 4 shows data for $\Phi / R_{\mathrm{CO} 2}$ obtained as a function of temperature for cabbage and tomato, respectively representing cold and hot climate plants. Analysis of these data with eqn. 5 correctly predicts the growth of these species as a function of temperature. Furthermore the results show that variation of substrate carbon conversion efficiency with temperature is the major determinant of the temperature response of growth in these species.

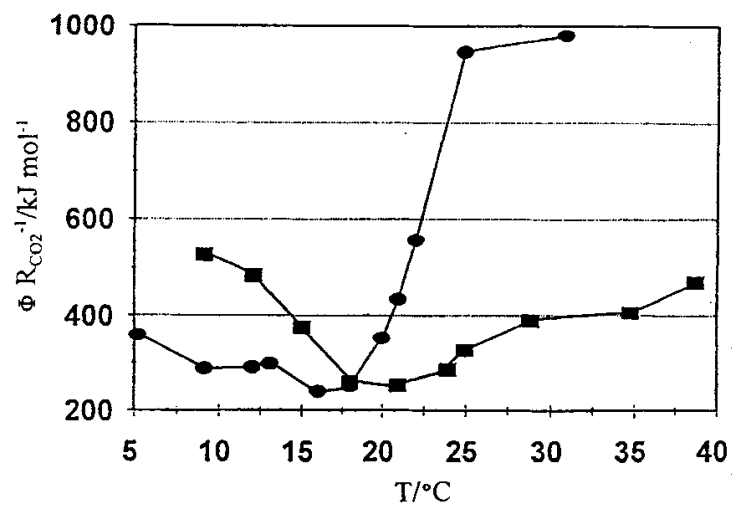

Fig. 4 The ratio of respiratory heat rate to $\mathrm{CO}_{2}$ rate measured as a function of temperature for cabbage ( $\bullet$ ) and tomato (ש). Data are from ref. 17.

\section{Explanation of Correlations between Growth Rates and Respiration Rates}

Our model provides two possible explanations for the existence of both positive and negative correlations between growth rate and a single measure of respiration rate. First, because growth rate is proportional to the difference between two different measures of respiration rate, increasing one rate can lead to either an increase or a decrease in growth rate, depending on the behavior of the other measure of respiratory rate. Second, we have observed that an isokinetic temperature often exists for respiration rates of plants in a wideranging population of a species $(16,18)$. If growth rate and respiration rate are both measured at temperatures well above or well below the isokinetic temperature, a positive correlation will be found. But, if respiration and growth rate are not measured at the same temperature and the temperatures of measurement happen to span the isokinetic temperatue, a negative correlation will result. Of course no correlation will be found if measurement of either variable is at an isokinetic temperature.

\section{DISCUSSION}

Much remains to be done to further test the proposed model, but results to date strongly support the validity of the model shown in fig. 1 and its quantitative interpretation in equations 1-5. The results further show that this model is certainly more useful than previous physiological plant growth models for predicting field growth rates and stress responses from laboratory measurements of metabolism. 
Data such as those in fig. 4 challenge current thinking about the nature of the cellular events at extresae environmental conditions that limit growth ranges of plants. Loss of structure, i.e. inactivation of enzymes a id loss of lipid membrane integrity, has been regarded as the cause of plant stress at extreme conditions. However the data in fig. 4 show that temperatures limiting plant viability can be predicted solely from energy considerations, without consideration of structures. The fact is that cellular and organelle structure and function are inseparable. Energy gradients are necessary to maintain the organization of cellular structur s, and cellular structures are necessary to maintain the energy gradients. Understanding the necessity for the existence of energy gradients in a plant is necessary to correctly interpret environmental effects on plant growth. According to the second law of thermodynamics, an energy gradient continuously increases the entropy of the surroundings, thus imposing a continuous loss of energy on the plant. Because this rate of energy loss depends on the environmental conditions, simultaneous measurement of $\Phi$ and $\mathrm{R}_{\mathrm{CO} 2}$ as functions of environmental variables is absolutely necessary to understand the energetics of plant growth in a variatle environment, i.e. in the field.

Only a few sets of simultaneous measurements of $\mathrm{R}_{\mathrm{CO} 2}$ and $\Phi$ as functions of environmental variables have as yet been collected. In addition to the data shown in figs. $2-4, \mathrm{R}_{\mathrm{CO} 2}$ and $\Phi$ data have been collected on radish tissues as functions of $\mathrm{N}, \mathrm{P}$, and $\mathrm{K}$ concentrations (19) and on eucalypt leaf tissue for the purpose of selection of breeding stock (20). Future data collection as a function of the concentration of toxins (e.g. salt, hea ry metals, ozone), and water activity should rapidly provide data similar to that for temperature on the mechanisms of the effects of these environmental variables on plant growth. Calorimetric methods should also be useful for study of phytopathogens, cold-hardening and photodamage, and for monitoring the physiological state of crop plants (e.g. see 21). Crop plants typically tolerate a narrower range of stresses than do their wild relatives, so there is much that can be done to improve crop varieties (e.g. see 22). The methods presented here should provide the means for rapidly moving forward in this area.

Perhaps the methods presented here and the knowledge to be gained thereby are the key to another green revolution, but there is much yet to be done to prove the feasibility of actually improving crop productivity through calorimetric measurements. There are assumptions inherent in the methods and model presented that need to be validated. Measurements of respiration rates over a few minutes to hours provide only a sincle snapshot in space and time. How should this snapshot be projected as the plant ages and environmental conditions change? How can measurements made on a small bit of tissue be used to accurately represent the growth and metabolic activity of a large plant? Which tissue should be used, and for which purposes? Another assumption is that responses to short-term (hours) environmental changes accurately respresent plant responses in the field. That is, acclimatization is either limited or proportionate to the short-term laboratory response measured. Use of the model to predict growth rates further assumes a constant proportionality between growth rate (structural biomass formation) in the light and growth rate in the dark across a population of plants under consideration. All of these assumptions are testable with time and effort.

The emphasis on respiration rates as a measure of plant growth rates challenges the current emphasis on photosynthesis as the determinant of plant productivity. Although it is a difficult message to convey to plant biologists, our work suggests that research on the thermodynamics of plant growth is more likely to lead to rapid improvements in plant productivity than work in photochemistry and photobiology. We think calorimetric measurements on plant metabolism will provide the key for quickly unlocking the current stasis (e.g. see 23) in the green revolution.

\section{ACKNOWLEDGEMENTS}

The authors appreciate the support for this work received from Brigham Young University, the University of California, Davis, and from C. N. R. S. to L.D.H. during a stay at the Laboratoire de Thermodynamique it Génie Chimique, Université Blaise Pascal, Clermont-Ferrand, France while on leave from BYU. 


\section{REFERENCES}

1. T. C. Tso. Science 273,1478 (1996)

2. G. Pauli. The Second Green Revolution. Ten Nobels for the Future - Paths to Sustainable Development. Milano, 5-7 Jine 1996.

3. W. G. Hopkins. Introduction to Plant Physiology, pp. 251-261. John Wiley, New York (1995).

4. P. S. Dasgupta. Scientific American 272, 40-45 (1995).

5. G. J. Kelly and E. Latzko. Photosynthesis. Chap. IV in Progress in Botany, Vol. 56 (H.-D. Behnke, U. Luttge, K. Esser, J. W. Kadereit, and M. Runge, eds.), pp. 134-164. Springer-Verlag, Berlin (1995).

6. N. R. Chiariello, H. A. Mooney and K. Williams. Growth, carbon allocation and cost of plant tissues. Chap. 15 in Plant Physiological Ecology (R. W. Pearcy, J. R. Ehleringer, H. A. Mooney and P. W. Rundel, eds.), pp. 327-365. Chapman and Hall, London (1989).

7. R. M. Gifford and L. T. Evans. Ann. Rev. Plant Physiol. 32, 485-509 (1981).

8. C. J. Nelson. Plant Physiol. Biochem. 26, 543-554 (1988).

9. H. G. Jones. Plant and Microclimate, 2nd edition, pp. 163-214. Cambridge University Press, Cambridge (1992).

10. L. D. Hansen, D. K. Taylor, B. N. Smith and R. S. Criddle. Russian J. of Plant Physiol. 43, 691-697 (1996).

11. L. E. Schrader. Selection for metabolic balance in maize. In Exploitation of Physiological and Genetic Variability to Enhance Crop Productivity (J. E. Harper, L. E. Schrader and R. W. Howell, eds.), p 79. American Society of Plant Physiologists, Rockville, MD (1985).

12. L.D. Hansen, M.S. Hopkin, D.R. Rank, T.S. Anekonda, R.W. Breidenbach and R.S. Criddle. Planta 194, 77-85 (1994)

13. J. Yamaguchi. J. Fac. Agric. Hokkaido Univ. 59, 59-129 (1978).

14. R. S. Criddle, R. W. Breidenbach and L. D. Hansen. Thermochim. Acta 193,67-90 (1991).

15. L.D. Hansen, M.S. Hopkin, D.K. Taylor, T.S. Anekonda, D.R. Rank, R.W. Breidenbach and R.S. Criddle. Thermochim. Acta, 250, 215-232 (1995).

16. D.K. Taylor, D.R. Rank, D.R. Keiser, B.N. Smith, R.S. Criddle and L.D. Hansen. The Relation Between Plant Growth and Respiration: Temperature Effects in Maize, in preparation.

17. R.S. Criddle, B.N. Smith, L.D. Hansen. A respiration based description of plant growth rate responses to temperature, Planta, in press (1996).

18. R. S. Criddle, M. S. Hopkin, E. D. McArthur and L. D. Hansen. Plant, Cell \& Environment 17, 233-243 (1994).

19. K. L. Hilt, D. R.Rank, M. A. Cheney, A. J. Fontana, L. D. Hansen and R.S. Criddle. "The relation between growth and respiration: Effects of limiting $\mathrm{N}, \mathrm{P}$, and $\mathrm{K}$ on growth of radish seedlings" Planta, submitted.

20. T. S. Anekonda, R. S. Criddle, M. J. Bacca and L. D. Hansen. Respiration-based selection strategies for breeding super or eucalypts and prediction of biomass quality using microcalorimetry in eucalyptus plantations. CRC-IUFRO Conferen:e, Hobart, Australia, Feb. 1995.

21. A. A. Gardea, Y. M. Moreno, A. N. Azarenko, L. D. Daley and R. S. Criddle. J. Am. Soc. Hort. Sci., 119, 756-760 (1994).

22. W. Feng, L. Ning, L. S. Daley, Y. Moreno, A. Azarenko and R. S. Criddle. Plant Physiol. Biochem. 32, 591-598 (1994).

23. L. R. Brown. World grain production falls. In Vital Signs 1996 (L. R. Brown, C. Flavin, and H. Kane, eds.), pp. 24-25. W. W. Norton \& Co., New York (1996). 